\title{
A Study On Psychological Variables On Women Sports Participation Levels In University
}

\author{
Dr. A. Muthu ${ }^{1}$, Dr. V. Jayanth ${ }^{2}$, Dr. D. Sakthiganavel ${ }^{3}$ \\ ${ }^{I}$ Director of Physical Education, Krishnasamy College of Engineering \& Technology, Cuddalore Tamil Nadu, \\ India \\ ${ }^{2}$ Professor, Department of Physical Education and Sports Science, Annamalai University, Tamil Nadu, India \\ ${ }_{3}^{3}$ Professor and Head, Department of Physical Education, Pondicherry University, Puducherry, India
}

\begin{abstract}
This research is to examine whether the psychological variable on women have any impact on women's sports participation between Anna and Pondicherry Universities at different levels. The subject were (was) randomly selected from Anna University in Tamil Nadu State (300 Players) and Pondicherry University (Central University) in Puducherry State (300 Players), India. The selected subjects were with a brief questionnaire, to find out their level of sports participation, anxiety, aggression and stress. Data obtained were subjected to find out statistical significance among the means using 3 (levels - Zonal, Inter - Zonal and University participations) X 2 (University - Anna and Pondicherry) Factorial analysis. The result proved that there were significant differences in selected psychological factors of the different level of women sports players. There was no significant difference in stress at different levels. There was no significant difference between the Anna and Pondicherry in anxiety, aggression and stress of the women sports players. It was concluded that anxiety, aggression, and stress play a vital role in the participation level of women players.
\end{abstract}

Key Worlds: Different Level of Players, Women Sports Participation, University, Anxiety, Aggression and Stress

\section{Introduction}

Norton PJ, et.al. Reported that although researchers have documented that social anxiety may occur in a wide range of interpersonal and performance situations, little attention has been paid to the potential influence of social anxiety on participation in athletics or physical activity. The performance demands of sport and potential social evaluative nature of exercise make it likely that social anxiety would generalize to these situations. Given the physical and psychological benefits of engaging in regular physical activity, avoidance of such activities by socially anxious individuals may have profound health consequences.

Harve E. et.al. Examined interrelationships among measures of stress, anxiety, depression, and physical illness in a proportional sample of college undergraduates $(N=184)$. Significant correlations were found in the stress-illness, anxiety-illness, depression- illness and anxiety-depression relationships. Partial correlations demonstrated that the stress-illness relationship remained significant, though lowered, when first anxiety and then depression were held constant. In the second phase of the research, the indices of stress, anxiety, depression, and illness were predicted to vary by both years in school and gender within this sample. Significant differences in reported stress and anxiety by year in school and in reported illness incidence by gender were found. Possible ties between these results and research on coping, social support, and gender roles are discussed. Hurvitz M, Weiss R studies reveal that participation of adolescents and young women in strenuous sports activity may lead to various metabolic and psychological derangements of clinical relevance to the endocrinologist. The most common manifestations encountered in practice are primary and secondary amenorrhea, reduced bone mineral density and eating disorders. The occurrence of all three together has been named "the athletic triad". The underlying hormonal drivers that lead to some of these manifestations are the reduced leptin level as well as the persistent low-grade stress response commonly observed in such females. Prather and Hunt reported that care and treatment of female runners will improve as further knowledge regarding the unique factors that affect them becomes available. For care and treatment being their most effective, current and recent information needs to be disseminated among health care providers, coaches, teachers, school administrators and parents. In young athletes, peer support and education are the most important factors in the success of detection and treatment. Individuals who have the female athlete triad are at significant risk for stress fractures and other injuries. Early detection and multidisciplinary treatment should begin after fractures are detected to reduce or prevent long-term adverse squealer to the bone.

\section{Methodology}

In this study the following statistical techniques were used to analyze the women's sports participation levels (1) Zonal level (2) Inter - Zonal level and (3) University level of Anna and Pondicherry Universities. (i) 3 
x 2 factorial design, (ii) Scheffe's post hoc test for factor A \& B, (iii) Simple test for interaction, (iv) Post hoc test for each cell. Anxiety was measured through the anxiety questionnaire. Spielberger (1979) developed it the Trait Anxiety questionnaire was given to all subjects. Twenty items were adopted from Spielbergers Trait Anxiety questionnaire for this investigation. The aggression of the college men players under study were measured through Aggression Scale test developed by Guru Pyari Mathur and Raj Kumari Bhatnagar (2004). The standard psychological tool devised by Everyly and Girdano's was used to quantify psychological stress. This test consists of 14 statements.

\section{Analysis And Discussion}

Table - I

Anxiety of the Sports Women of Different Levels of Participation in Anna and Pondicherry Universities

\begin{tabular}{|c|c|c|c|c|}
\hline \multicolumn{2}{|c|}{ UNIVERSITIES / LEVELS } & ZONAL & INTER - ZONAL & UNIVERSITY \\
\hline \multirow{3}{*}{ Anna } & Mean & 54.38 & 54.11 & 53.50 \\
\cline { 2 - 5 } & SD & 5.439 & 4.318 & 5.594 \\
\cline { 2 - 5 } & $\mathbf{N}$ & 155 & 115 & 30 \\
\hline \multirow{3}{*}{ Pondicherry } & Mean & 54.33 & 54.00 & 54.13 \\
\cline { 2 - 5 } & SD & 5.130 & 5.459 & 3.447 \\
\cline { 2 - 5 } & $\mathbf{N}$ & 177 & 93 & 30 \\
\hline
\end{tabular}

Table I - A

Factorial Analysis Of Variance on Anxiety of the Sports Women Participation Levels of Anna and Pondicherry Universities

\begin{tabular}{|l|c|c|c|c|}
\hline & Sum of Squares & df & Mean Square & F \\
\hline Factor A & 2.278 & 1 & 2.278 & 0.087 \\
\hline Factor B & 21.196 & 2 & 10.598 & 0.405 \\
\hline Factor AB & 6.858 & 2 & 3.429 & 0.131 \\
\hline Error & 15536.372 & 594 & 26.156 & \\
\hline
\end{tabular}

(The table values required for significance at .05 level of confidence for 1 and 594 and 2 and 594 are 3.89 and 3.04 respectively).

Table I shows that the mean values on anxiety of the Anna University sports women at Zonal, Inter Zonal and University levels were $54.38,54.11$ and 53.50 respectively. It also shows the mean values on anxiety of the Pondicherry University sports women at Zonal, Inter - Zonal and University levels were 54.33, 54.00 and 54.13 respectively. To test the significance of the differences in the means, the obtained data were subjected to statistical treatment using 2 (universities) x 3 (levels) Factorial Analysis of Variance (Factorial Anova). The obtained results were presented in Table I $-\mathrm{A}$.

Table I - A shows that the obtained ' $\mathrm{F}$ ' ratio on anxiety for factor ' $\mathrm{A}$ ' 0.087 which was lesser than the required table value 3.89 with $\mathrm{df} 1$ and 594 at .05 level of confidence. Hence, it was concluded that there was no significant difference between the Anna and Pondicherry University women players irrespective of their different levels of participation on anxiety. The table I - A also shows that the obtained ' $\mathrm{F}$ ' ratio on anxiety for factor 'B' 0.405 which was lesser than the required table value 3.04 with df 2 and 594 at .05 level of confidence. Hence, it was concluded that there was no significant difference among women players of different levels of participation irrespective of their University on anxiety. The table I - A shows that the obtained ' $F$ ' ratio for the factor ' $\mathrm{AB}$ ' 0.131 which was lesser than the required table value 3.04 with df 2 and 594 at .05 level of confidence. Hence, it was concluded that there was no significant difference between Anna and Pondicherry Universities women players of different levels of participation on anxiety.

Table - II

Aggression of the Sports Women of Different Levels of Participation in Anna and Pondicherry Universities

\begin{tabular}{|c|c|c|c|c|}
\hline \multicolumn{2}{|c|}{ UNIVERSITIES / LEVELS } & ZONAL & INTER - ZONAL & UNIVERSITY \\
\hline \multirow{3}{*}{ Anna } & Mean & 184.06 & 185.07 & 188.23 \\
\cline { 2 - 5 } & SD & 23.793 & 23.763 & 26.623 \\
\cline { 2 - 5 } & N & 155 & 115 & 30 \\
\hline \multirow{3}{*}{ Pondicherry } & Mean & 182.99 & 184.09 & 181.13 \\
\cline { 2 - 5 } & SD & 24.532 & 23.965 & 20.706 \\
\cline { 2 - 5 } & N & 177 & 93 & 30 \\
\hline
\end{tabular}


Table II - A

Factorial Analysis Of Variance on Aggression of the Sports Women Participation Levels of Anna and Pondicherry Universities

\begin{tabular}{|l|c|c|c|c|}
\hline \multicolumn{1}{|c|}{ Source } & Sum of Squares & df & Mean Square & F \\
\hline Factor A & 854.174 & 1 & 854.174 & 1.478 \\
\hline Factor B & 170.735 & 2 & 85.368 & 0.148 \\
\hline Factor AB & 495.620 & 2 & 247.810 & 0.429 \\
\hline Error & 343300.921 & 594 & 577.948 & \\
\hline
\end{tabular}

(The table values required for significance at .05 level of confidence for 1 and 594 and 2 and 594 are 3.89 and 3.04 respectively).

Table II shows that the mean values on aggression of the Anna University sports women at Zonal, Inter - Zonal and University levels were 184.06, 185.07 and 188.23 respectively. It also shows the mean values on aggression of the Pondicherry University sports women at Zonal, Inter - Zonal and University levels were 182.99, 184.09 and 181.13 respectively. Table II - A shows that the obtained ' $F$ ' ratio on aggression for factor 'A' 1.478 which was lesser than the required table value 3.89 with df 1 and 594 at .05 level of confidence. Hence, it was concluded that there was no significant difference between the Anna and Pondicherry universities women players irrespective of their different levels of participation on aggression. The table II - A also shows that the obtained ' $F$ ' ratio on aggression for factor ' $B$ ' 0.148 which was lesser than the required table value 3.04 with df 2 and 594 at .05 level of confidence. Hence, it was concluded that there was no significant difference among women players of different levels of participation irrespective of their University on aggression. The table II - A shows that the obtained ' $F$ ' ratio for the factor ' $A B$ ' 0.429 which was lesser than the required table value 3.04 with df 2 and 594 at .05 level of confidence. Hence, it was concluded that there was no significant difference between Anna and Pondicherry Universities women players of different levels of participation on aggression.

Table - III

Stress of the Sports Women of Different Levels of Participation in Anna and Pondicherry Universities

\begin{tabular}{|c|c|c|c|c|}
\hline \multirow{3}{*}{ UNIVERSITIES / LEVELS } & ZNONAL & INTER - ZONAL & UNIVERSITY \\
\hline & SD & 4.885 & 25.65 & 23.93 \\
\cline { 2 - 5 } & $\mathbf{N}$ & 155 & 3.996 & 5.252 \\
\cline { 2 - 5 } & Mean & 23.64 & 115 & 30 \\
\hline \multirow{3}{*}{ Pondicherry } & SD & 5.293 & 25.28 & 24.20 \\
\cline { 2 - 5 } & N & 177 & 3.860 & 307 \\
\cline { 2 - 5 } & & 93 & 30 \\
\hline
\end{tabular}

Table III - A

Factorial Analysis of Variance on Stress of the Sports Women Participation Levels of Anna and Pondicherry Universities

\begin{tabular}{|l|c|c|c|c|}
\hline Source & Sum of Squares & df & Mean Square & F \\
\hline Factor A & 0.00843 & 1 & 0.00843 & 0.0037 \\
\hline Factor B & 450.910 & 2 & 225.455 & $9.985^{*}$ \\
\hline Factor AB & 9.084 & 2 & 4.542 & 0.201 \\
\hline Error & 13412.680 & 594 & 22.580 & \\
\hline
\end{tabular}

*Significant at .05 level

(The table values required for significance at .05 level of confidence for 1 and 594 and 2 and 594 are 3.89 and 3.04 respectively).

Table III - B

The Scheffe's Test for the Differences between Paired Means on Stress

\begin{tabular}{|c|c|c|c|c|}
\hline \multicolumn{2}{|c|}{ MEANS } & \multirow{2}{*}{ Mean Difference } & \multirow{2}{*}{ Confidence Interval } \\
\hline Zonal & Inter - Zonal & University & $1.90 *$ & 1.891 \\
\hline 23.59 & 25.49 & - & 0.48 & 0.423 \\
\hline 23.59 & - & 24.07 & 1.42 & 1.382 \\
\hline
\end{tabular}

* Significant at .05 level

Table III shows that the mean values on stress of the Anna and Pondicherry universities sports women at Zonal, Inter - Zonal and University levels were 23.53, 25.65 and 23.93 respectively. It also shows the mean values on stress of the Pondicherry University sports women at Zonal, Inter - Zonal and University levels were 23.64, 25.28 and 24.20 respectively. To test the significance of the differences in the means, the obtained data were subjected to statistical treatment using 2 (Universities) x 3 (Levels of participation) Factorial Analysis of Variance (Factorial Anova). Table III - A shows that the obtained ' $F$ ' ratio on stress for factor ' $A$ ' 0.0037 which 
was lesser than the required table value 3.89 with df 1 and 594 at .05 level of confidence. Hence, it was concluded that there was no significant difference between the Anna and Pondicherry university women players irrespective of their different levels of participation on stress. The table III - A also shows that the obtained ' $\mathrm{F}$ ' ratio on stress for factor ' $\mathrm{B}$ ' 9.985 which was higher than the required table value 3.04 with df 2 and 594 at .05 level of confidence. Hence, it was concluded that there was a significant difference among women players of different levels of participation irrespective of their Universities on stress. Table III - B shows the mean difference between Zonal and Inter - Zonal level players, Zonal and University level players and Inter - Zonal and University level players on stress irrespective of their University were 5.57, 11.15 and 5.58 respectively which were higher than the required confidence interval values $1.891,0.423$ and 1.382 respectively at .05 level of significance. The table III - A shows that the obtained ' $F$ ' ratio for the factor ' $A B$ ' 0.201 which was lesser than the required table value 3.04 with df 2 and 594 at .05 level of confidence. Hence, it was concluded that there was no significant difference between Anna and Pondicherry Universities women players of different levels of participation on stress.

\section{Discussions On Findings}

The results of the study indicated that there was no significant difference between Anna and Pondicherry Universities women players irrespective of their levels of participation (Zonal, Inter - Zonal and University) on anxiety, aggression and stress. Moreover, significant differences were found among Zonal, Inter - Zonal and University level sports women players irrespective of their Universities (Anna and Pondicherry) on stress. Further, the results of the study further showed that no significant differences were found among Zonal, Inter - Zonal and University level sports women players irrespective of their University (Anna and Pondicherry) on anxiety and aggression. The results of the study also indicated that there was no significant difference in the interaction effect between Anna and Pondicherry Universities sports women players of different levels of participation on anxiety, aggression and stress.

Sharma SV et.al. (2009) identified pathways used by psychosocial factors to influence physical activity in middle-school girls and concluded psychosocial factors use to influence physical activity of school girls. The findings of this study are in agreement with the findings of Skirka N. (2000) who found under certain conditions of stress some people stay physically and psychologically healthy while others become ill and found that there was a significant positive correlation between perceived stress and psychological symptoms among college varsity athletes.

\section{Conclusions}

The results of the study showed that there was no significant difference between Anna and Pondicherry Universities' sports women players of different levels of participation on selected variables such as anxiety, aggression and stress. Hence, the investigator's third hypothesis was accepted.

\section{References}

[1] Harve E. Rawsona, Kimberly Bloomera, Amanda Kendalla. Stress, Anxiety, Depression, and Physical Illness in College Students Psychology, Hanover College, 155(4), 1994, 321-330.

[2] Hurvitz M, Weiss R. The young female athlete, Pediatr Endocrinol Rev, 7(2), 2009, 123-9.

[3] Norton PJ, Burns JA, Hope D A, Bauer B K. Generalization of social anxiety to sporting and athletic situations: gender, sports involvement, and parental pressure, Depress Anxiety, 12(4), 2000, 193-202.

[4] Prather H, Hunt D. Issues unique to the female runner, Phys Med Rehabil Clin N Am, 16(3), 2005, 691-709.

[5] Sharma SV, Deanna M. Hoelscher, Steven H. Kelder, R.Sue Day, and Albert Hergenroeder. A path analysis to identify the psychosocial factors influencing physical activity and bone health in middle - school girls, J Phys Act Health, 6(5), 2009, 606-16.

[6] Skirka N. The relationship of hardiness, sense of coherence, sports participation and gender to perceived stress and psychological symptoms among college students, J Sports Med Phys Fitness, 40(1), 2000, 63-70. 